\title{
Particle Liquid Water Content and Aerosol Acidity Acting as Indicators of Aerosol Activation Changes in Cloud Condensation Nuclei (CCN) during Pollution Eruption in Guangzhou of South China
}

\author{
Junyan Duan', Rui Lyu', Yanyu Wang1, Xin Xie', Yunfei Wu², Jun Tao³, Tiantao Cheng, ${ }^{4 *}$, \\ Yuehui Liu ${ }^{1}$, Yarong Peng ${ }^{1}$, Renjian Zhang ${ }^{2 *}$, Qianshan $\mathrm{He}^{6}$, Wei $\mathrm{Ga}^{6}$, Xianming Zhang ${ }^{7}$, \\ Qian Zhang ${ }^{7}$
}

${ }^{1}$ Shanghai Key Laboratory of Atmospheric Particle Pollution and Prevention (LAP $\left.{ }^{3}\right)$, Department of Environmental Science and Engineering, Fudan University, Shanghai 200438, China

${ }^{2}$ Key Laboratory of Region Climate-Environment Research for Temperate East Asia (TEA), Institute of Atmospheric Physics, Chinese Academy of Sciences, Beijing 100029, China

${ }^{3}$ South China Institute of Environmental Sciences, Ministry of Environmental Protection, Guangzhou 510655, China

${ }^{4}$ Department of Atmospheric and Oceanic Sciences and Institute of Atmospheric Sciences, Fudan University, Shanghai

200438, China

${ }^{5}$ Institute of Eco-Chongming (SIEC), Shanghai 200062, China

${ }^{6}$ Shanghai Meteorological Bureau, Shanghai 20030, China

${ }^{7}$ Wireless Product R\&D Institute, ZTE Corporation, Shenzhen 518057, China

\begin{abstract}
Atmospheric pollution has been found to modify the hygroscopicity of particles and the ability of aerosols to become cloud condensation nuclei $(\mathrm{CCN})$. Aerosols and the bulk CCN were measured in urban Guangzhou during pollution periods in January 2016, and the particle liquid water content (PLWC) and aerosol acidity (Aero-pH) were calculated to examine their possible effects on aerosols' CCN activation. The results demonstrate that the PLWC and Aero-pH likely play key roles in enhancing aerosol activation during the early stages of pollution episodes. The analysis of the calculated and the observed data shows that CCN, PLWC, Aero-pH and water-soluble inorganic matter (WSIM) are closely linked to each other, particularly at night, and Aero-pH and PLWC act as pre-occurring indicators of activated aerosols and aerosol activity, respectively, during the rapid onset of pollution. In theory, the feedback between chemical reactions, aerosol acidity and particle water content accounts for the changes in aerosol activation accompanying particle accumulation and aging. Our research provides insights into the swift formation of particle pollution characterized by secondary aerosols and suggests a possible approach to tracking or characterizing its effects on the activation of aerosols into $\mathrm{CCN}$ without requiring $\mathrm{CCN}$ or aerosol number measurements.
\end{abstract}

Keywords: Aerosol acidity; Particle water content, CCN; Pollution.

\section{INTRODUCTION}

Atmospheric pollutions with fine particles as the main pollutant occurring in China, known as haze or polluted disastrous weather, have great impacts on air quality, human health, even atmospheric circulation and climate (Bollasina et al., 2011). These particulate matter (PM) always comes

\footnotetext{
* Corresponding author.

Tel.: (86) 21-6564 3230; Fax: (86) 21-6564 2080

E-mail address: ttcheng@fudan.edu.cn (T. Cheng); zrj@mail.iap.ac.cn (R. Zhang)
}

from primary emissions and secondary products of gas-toparticle conversion (Zhang et al., 2015). In the atmosphere, PM usually ages through physical and chemical processes, even far different from its pristine, and then changes aerosol physical, chemical, optical and hygroscopic properties (Jimenez et al., 2009).

In addition to sufficient precursors, atmospheric pollutions provide favorable meteorological conditions for PM transformation. High relative humidity $(\mathrm{RH})$, low planetary boundary layer height (PBLH) and weak wind enhance particle liquid water content (PLWC) by vapor uptake and adsorption (Wu et al., 2018), and then facilitate secondary species formation by heterogeneous and aqueous reactions (Wang et al., 2016). The PLWC significantly contributes to 
ambient aerosol mass (Nguyen et al., 2016), plays an important role in the generation and evolution of secondary aerosols (Hodas et al., 2014), and alters particle physical and chemical properties (Tan et al., 2017). PLWC extinction has been reported to account for $34 \%$ of the total extinction coefficient (Jung et al., 2009), and the scattering coefficient can increase to 5 -fold that of dry particles at $90 \% \mathrm{RH}$ due to high water volume occupancy (Wong et al., 2015). PLWC induced by anthropogenic secondary inorganic aerosols (SIAs) may significantly influence air quality (Khlystov et al., 2005) and regulate biogenic aqueous secondary organic aerosol (SOA) formation (Hodas et al., 2014). During pollution periods, the sulfate increase observed in China is responsible for $\mathrm{SO}_{2}$ oxidation in aqueous phase with various atmospheric oxidants (Elser et al., 2016). At high RHs, the formation of sulfate and nitrate is attributed to the aqueous oxidation of $\mathrm{SO}_{2}$ and $\mathrm{NO}_{x}$ promoted by $\mathrm{NH}_{3}$ neutralization, in particular of nocturnal times with rich ammonia (Cheng et al., 2016; Wang et al., 2016).

The particle acidity determined by aqueous $\mathrm{H}^{+}$links with PLWC and water-soluble species, and influences atmospheric chemistry through providing favorable reaction conditions, such as atmospheric behavior of gaseous pollutants and $\mathrm{pH}$ dependent heterogeneous chemical processes occurring on aerosol surfaces (Behera and Sharma, 2012). PLWC can modify particle ability to be activated into cloud condensation nuclei (CCN) by aerosol aging (Che et al., 2016). Cubison et al. (2008) and Mochida et al. (2006) argued that detailed chemical composition and mixing state should be considered in calculating aerosol $\mathrm{CCN}$ activity. Numerous studies have explored the regional pollution events occurring in China, and revealed chemical composition changes of pollutants under high RH conditions during these pollutions (An et al., 2019). Additionally, many studies have attempted to deduce the changes of particle hygroscopicity during polluted periods, and their effects on PLWC and aerosol pH, which determines aerosol ability to be $\mathrm{CCN}$ and cloud physical properties (Leng et al., 2014; Che et al., 2016; Xie et al., 2019). Recently, attention has been increasingly paid to the relationship of PLWC and aerosol acidity with particulate chemical reactions (Cheng et al., 2016; Wu et al., 2018). Nevertheless, up to now, there are relatively limited studies on the relationship between $\mathrm{CCN}$, aerosol water and acidity during pollution rapid formation.

Guangzhou is the largest megacity of the Pearl River Delta (PRD) in South China, and similar studies on the relationships between air pollution, aerosol chemical evolution, and $\mathrm{CCN}$ are relatively rare in this region. Based on analysis of typical pollution cases occurring in January 2016, this paper offers a thorough insight into how the aerosol activation into CCN changes with PLWC and aerosol acidity during pollution eruption in urban environment of Guangzhou. Our purpose is to unravel their association, and to attribute aerosol water-soluble components and potential chemical causes.

\section{MATERIAL AND METHODS}

\section{Measurements}

Intensive observations were conducted at the monitoring station of South China Institute of Environmental Science (SCIES), Ministry of Ecology and Environment (MEE), located in Guangzhou of China $\left(23.07^{\circ} \mathrm{N}, 113.21^{\circ} \mathrm{E}\right)$, during January 2016. Water-soluble ions (WSIs) of $\mathrm{SO}_{4}{ }^{2-}, \mathrm{NO}_{3}{ }^{-}$, $\mathrm{Cl}^{-}, \mathrm{NH}_{4}^{+}, \mathrm{Na}^{+}, \mathrm{K}^{+}, \mathrm{Ca}^{2+}$ and $\mathrm{Mg}^{2+}$ in fine particulate matter $\left(\mathrm{PM}_{2.5}\right)$ and atmospheric trace gases of $\mathrm{NH}_{3}, \mathrm{HCl}$ and $\mathrm{HNO}_{3}$ were simultaneously measured by a semi-continuous monitoring system of In situ Gas and Aerosol Composition (IGAC) (Model S-611; Fortelice International Co., Ltd., Taiwan) with a temporal resolution of $1 \mathrm{~h}$. A combination of CCN counter (CCN-100; DMT, Longmont, CO, USA), Scanning Mobility Particle Sizer (SMPS 3080; TSI Inc., Shoreview, MN, USA) and Aerodynamic Particle Sizer (APS) was used to measure bulk CCN and aerosols in sizes of $13 \mathrm{~nm}$ to $10 \mu \mathrm{m}$. The supersaturation (SS) of CCN counter was set for five levels within $0.1-0.8$ during the campaign, and aerosol activity (AR) defined as the proportion of aerosols activated into $\mathrm{CCN}$ at $0.4 \mathrm{SS}$ was used in the following sections. The condensation nuclei $(\mathrm{CN})$ refers to integrated number concentration of size-resolved particles. Gas species of $\mathrm{SO}_{2}, \mathrm{NO}_{x}, \mathrm{CO}$ and $\mathrm{O}_{3}$ were measured by gas analyzers (Models 43i, 42i, 48i and 49i; Thermo Fisher Scientific Inc., USA). PM $_{2.5}$ was measured by a set of tapered element oscillating microbalance (1400a TEOM; Rupprecht \& Patashnick Co., Inc., USA). Meteorological parameters were measured using an automatic weather monitoring system (MAWS201; Vaisala Company, Finland).

\section{Methodology}

Several models have been developed and used widely to estimate aerosol pH (Aero-pH) and PLWC using RH, aerosol mass and chemical composition, such as SCAPE2 (Meng et al., 1995), ISORROPIA (Nenes et al., 1998), AIM (Clegg et al., 1998) and AIOMFAC (Ganbavale et al., 2015). Briefly, the ISORROPIA-II is a thermodynamic equilibrium model to calculate the physical state and composition of atmospheric inorganic aerosols, and to predict PLWC and Aero-pH. It can run in the reverse mode based on aerosol content, whereas in the forward mode based on both aerosol and gas concentrations ( $\mathrm{Xu}$ et al., 2015). In this study, the ISORROPIA-II model was applied in the forward mode to calculate the equilibrium composition of aerosol system $\left(\mathrm{Na}^{+}-\mathrm{K}^{+}-\mathrm{Ca}^{2+}-\mathrm{Mg}^{2+}-\mathrm{NH}_{4}{ }^{+}-\mathrm{SO}_{4}{ }^{2-}-\mathrm{NO}_{3}{ }^{-}-\mathrm{Cl}^{-}-\mathrm{H}_{2} \mathrm{O}\right)$, which has been demonstrated a higher ability in simulating Aero-pH than the reverse mode (Guo et al., 2015; Hennigan et al., 2015). Input to the ISORROPIA-II includes a month's data of WSI compositions, gaseous precursors (e.g., $\mathrm{NH}_{3}, \mathrm{HNO}_{3}$, $\mathrm{HCl}), \mathrm{RH}$ and atmospheric temperature (T). Given high RHs in most cases (average of 67\%), we run the model under the assumption that aerosol solutions are metastable, which often provides superior results to the stable-state solution (solid + liquid) and has been commonly applied in previous pH predictions (Bougiatioti et al., 2016; Weber et al., 2016).

The Aero-pH of bulk particles is calculated by the following Eq. (1):

$\mathrm{pH}=-\log _{10} \frac{1000 H_{\text {air }}^{+}}{A L W C} \approx-\log _{10} \frac{1000_{\text {air }}^{+}}{A L W C_{i}}$ 
where $H_{\text {air }}{ }^{+}$is the equilibrium hydronium ion concentration in particles per air volume, and $A L W C_{i}$ is the aerosol water content output from ISORROPIA-II, which ignores the water content contributed by organic species.

\section{$P L W C$ and $p H$ Validation}

PLWC can also be calculated using aerosol size, number and hygroscopicity, such as size-resolved hygroscopic growth factor (HGF) and particle number size distribution (PNSD). Compared with the HGF-PNSD method, the ISORROPIA-II method has been demonstrated an effective pathway to quantitatively calculate PLWC owing to its rigorous calculation, performance and computational speed (Guo et al., 2015; Xu et al., 2015; Wu et al., 2018). In addition, a comparison illustrates that the PLWCs calculated from the ISORROPIA-II model and the E-AIM model agree well with each other (Fig. S1).

The thermodynamic model often predict PLWC and Aero-pH based solely on amount of aerosol water-soluble inorganic components. In fact, although organic matter is an important component of particulate pollutants in China (Huang et al., 2014), whereas there are a few water-soluble organic components (WSOCs) in aerosols, such as some organic acids (Sun and Ariya, 2006). In winter of Guangzhou, major WSIs and organic carbon (OC) account for about $43 \%$ and $11.4 \%$ of $\mathrm{PM}_{2.5}$, respectively (Tao et al., 2014). The effects of acidic and non-acidic WSOC species on $\mathrm{pH}$ mostly offset each other, and Aero-pH is sufficiently constrained by inorganic constituents alone and without liquid-liquid phase separation (Battaglia et al., 2019). Guo et al. (2015) calculated the contribution of organic fraction to PLWC, and found that $\mathrm{pH}$ prediction is not highly sensitive to water uptake by organic species. Liu et al. (2017) estimated that the particle water induced by organic matter is $5 \%$ of total PLWC in Beijing, and shows a negligible contribution to Aero-pH. In general, ignoring the water content contributed by organic species may cause a very minor bias in predicting Aero-pH from the model (Guo et al., 2018).

In this study, inorganic WSIs in particles and atmospheric gases measured by IGAC were used in running the ISORROPIA-II model to calculate PLWC and Aero-pH. Compared to filter measurements, online measurements have a higher time resolution, and reduce errors caused by loss of semi-volatile species through evaporation during sampling and observation. The good linear correlation between filter and online measurements certifies the accuracy and collection efficiency of ion concentrations measured by online instrument (e.g., AIM) (Hu et al., 2014). The ISORROPIA-II model can lead to a lower predicted Aero-pH due to repartitioning of ammonia when gas-phase data are not available (Hennigan et al., 2015), and Aero-pH is less sensitive to $\mathrm{NH}_{3}$ even if there is some error in $\mathrm{NH}_{3}$ (Guo et al., 2017). We compared the ammonium concentrations between measured and predicted by the ISORROPIA-II model, considering gas-particle partitioning of $\mathrm{NH}_{3}-\mathrm{NH}_{4}{ }^{+}$. The resultant relationship illustrates a good agreement between measured and modeled $\mathrm{NH}_{4}{ }^{+}\left(\mathrm{R}^{2}\right.$ $=0.98$ ), and confirms that the ISORROPIA-II model have a strong capability to partition and predict aerosol inorganic species (Fig. S2). Hence, the ISORROPIA-II model can estimate PLWC and Aero-pH fairly well, and provide reliable data for the following analysis.

\section{RESULTS}

\section{Overview of Pollution Periods}

Fig. 1 shows time series of hourly $\mathrm{PM}_{2.5}$, PLWC and major WSIs, Aero-pH, and CCN from 2 to 10 January. Clearly, Guangzhou suffers from two particulate pollution events occurring in Episode I (2-4 Jan.) and Episode II (7-10 Jan.), persisting for more than four days, respectively. In general, $\mathrm{PM}_{2.5}$ experiences several fluctuations with rapidly increasing and decreasing (i.e., a-f stages) and far exceeds the PM criteria for judging air pollution $\left(75 \mu \mathrm{g} \mathrm{m}^{-3}\right)$ in most times. The $\mathrm{PM}_{2.5}$ mass exhibits nonlinear increases during the $\mathrm{a}-\mathrm{f}$ stages, in particular of the a stage with an hourly maximum concentration of $148 \mu \mathrm{g} \mathrm{m}^{-3}$ on 2 Jan. that is more than 2 times the Chinese National Ambient Air Quality Standard (24hour mean of $75 \mu \mathrm{g} \mathrm{m}^{-3}$ ) and about 6 times that of the World Health Organization Standard (24-hour mean of $25 \mu \mathrm{g} \mathrm{m}^{-3}$ ). In terms of hourly $\mathrm{PM}_{2.5}$, the mean PLWCs are 9.4, 16.5 and $27.9 \mu \mathrm{g} \mathrm{m}^{-3}$ under air qualities of excellent $\left(\mathrm{PM}_{2.5} \leq 35 \mu \mathrm{g} \mathrm{m}^{-3}\right)$, $\operatorname{good}\left(\mathrm{PM}_{2.5}: 35-75 \mu \mathrm{g} \mathrm{m}^{-3}\right)$ and polluted $\left(\mathrm{PM}_{2.5} \geq 75 \mu \mathrm{g} \mathrm{m}^{-3}\right)$ grades, respectively, and the corresponding averages of AeropHs are 2.5, 2.9 and 3.4, exhibiting an obvious acidic feature (Table 1). These Aero-pHs are almost one half of the average $\mathrm{pH}$ values of 5.4 to 6.2 under haze conditions of the North China Plain (NCP) (Cheng et al., 2016; Ding et al., 2019).

In addition, as PM levels worsening, CCN ( $\mathrm{SS}=0.4$, thereafter) and condensation nuclei $(\mathrm{CN})$ increase by $2-3$ times, whereas aerosol activity decreases by about $16 \%$ (Table 1). In contrast to clean days, although $\mathrm{CCN}$ number increases with PM due to more soluble (e.g., secondary aerosols) and larger particles, the mean $\mathrm{AR}$ ratios $(\mathrm{CCN} / \mathrm{CN}$ at $0.4 \mathrm{SS}$, thereafter) have lower values in polluted days due to $\mathrm{CN}$ grows faster than CCN (Leng et al., 2014). Moreover, insoluble and low-soluble substances (e.g., black carbon) increase and then possibly modify particle hygroscopicity and aerosol activation efficiency. At the same time, along with $\mathrm{PM}$ rising, nitrogen oxidation ratio (NOR) magnifies by $167 \%$, while sulfur oxidation ratio (SOR) reduces by rough $41.5 \%$ (Table 1 ). Their opposite trends indicate that the formation of secondary chemical compositions (e.g., $\mathrm{SO}_{4}{ }^{2-}, \mathrm{NO}_{3}{ }^{-}$and $\mathrm{NH}_{4}{ }^{+}$) plays an important role in triggering and persisting particle pollutions, and increasing PM likely enhances nitrogen oxides-nitrate conversion but suppresses sulfur oxides-sulfate conversion (Pöschl et al., 2009). Subsequently, the changes in aerosol WSI species especially nitrate and sulfate may exert influence on PLWC and aerosol acidity. Noticeably, during the whole polluted periods, there is no significant difference of time-averaged PLWC, Aero$\mathrm{pH}$ and other concerns between winter daytime and night (Table S1). Compared with weekdays, most of concerned parameters such as PLWC, Aero-pH, NOR and CCN show relatively higher values on weekends (Table S2), implying that traffic emission (i.e., particle and gaseous precursors), as one of major local anthropogenic source, contributes to some extent to changes of WSI species, PLWC and Aero-pH on short-term scales (Tao et al., 2014). 

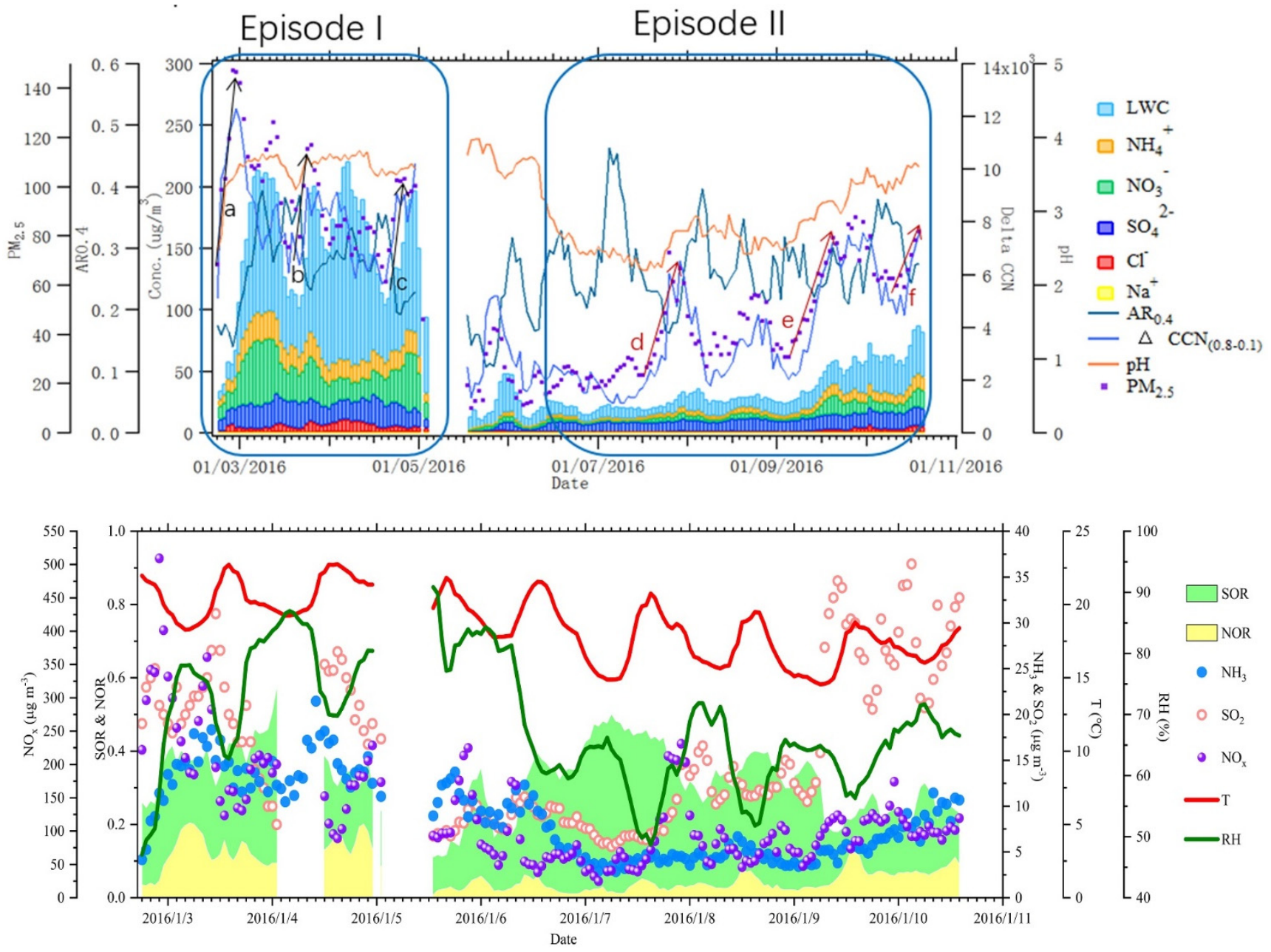

Fig. 1. Time series of hourly mean $\mathrm{PM}_{2.5}$, aerosol liquid water content (LWC) and acidity $(\mathrm{pH})$, dominant water-soluble ions and trace gases, increment of cloud condensation nuclei (CCN) between supersaturation (SS) at 0.1 and 0.8 , and aerosol activity to be CCN (AR) at $0.4 \mathrm{SS}$ from 2 to $10 \mathrm{Jan} .2016$.

Table 1. Statistics of aerosol acidity (Aero-pH), aerosol liquid water content (LWC), nitrogen oxidation ratio (NOR), sulfur oxidation ratio (SOR), cloud condensation nuclei $(\mathrm{CCN})$, condensation nuclei $(\mathrm{CN})$ and ratio of $\mathrm{CCN} / \mathrm{CN}$ at three $\mathrm{PM}_{2.5}$ levels.

\begin{tabular}{|c|c|c|c|c|c|c|c|}
\hline $\begin{array}{l}\text { PM conc. } \\
\mu \mathrm{g} \mathrm{m}^{-3}\end{array}$ & $\begin{array}{l}\text { Aero-pH } \\
-\end{array}$ & $\begin{array}{l}\text { LWC } \\
\mu \mathrm{g} \mathrm{m}^{-3}\end{array}$ & $\begin{array}{l}\text { NOR } \\
-\end{array}$ & $\begin{array}{l}\text { SOR } \\
-\end{array}$ & $\begin{array}{l}\mathrm{CCN}_{0.4} \\
\mathrm{~cm}^{-3}\end{array}$ & $\begin{array}{l}\mathrm{CN} \\
\mathrm{cm}^{-3}\end{array}$ & $\begin{array}{l}\mathrm{CCN}_{0.4} / \mathrm{CN} \\
-\end{array}$ \\
\hline $\mathrm{PM}_{2.5}<35$ & $2.47 \pm 0.19$ & $9.38 \pm 2.0$ & $0.03 \pm 0.01$ & $0.41 \pm$ & $1390 \pm 325$ & $4772 \pm$ & $0.31 \pm 0.08$ \\
\hline $35<\mathrm{PM}_{2.5}<75$ & $2.89 \pm 0.36$ & $16.48 \pm 7.96$ & $0.05 \pm 0.03$ & $0.30 \pm 0.07$ & $2892 \pm 859$ & $11021 \pm 3527$ & $0.27 \pm 0.05$ \\
\hline $\mathrm{PM}_{2.5}>75$ & $3.40 \pm 0.20$ & $27.91 \pm 7.19$ & $0.08 \pm 0.02$ & $0.24 \pm 0.01$ & $4440 \pm 114$ & $16900 \pm 1818$ & $0.26 \pm 0.03$ \\
\hline
\end{tabular}

The ratio of water-soluble inorganic matter (WSIM) to $\mathrm{PM}_{2.5}$ represents a fraction of integrated WSI matter in $\mathrm{PM}_{2.5}$, and the present ratio in Guangzhou is higher than in other urban sites such as Beijing (28\%), Shanghai (36\%) and Chongqing (30\%) (Zheng et al., 2005; Yang et al., 2011; He et al., 2012). Although there are high values (e.g., over 0.7) in WSIM/PM 2.5 (Fig. 3), which is possibly caused by systematic errors of the online instruments especially for WSIM, and both measurements obtained from different instruments (Tao et al., 2014), WSIM/PM 2.5 is available to zoom into pollutant variability in advantage of high temporal resolution. Although different amplitudes and phases, AR and
WSIM/PM 2.5 on average have a similar tri-modal pattern of diurnal variation, with higher values at night, noon or afternoon, and AR is $2-3$ hours slower than WSIM/PM 2.5 in phase (Fig. S3). CCN and $\mathrm{PM}_{2.5}$ almost show similar diurnal variations except for the morning rush hours, and their high values mainly distribute in nocturnal times. However, PLWC and Aero- $\mathrm{pH}$ are relatively insensitive to outside conditions, and seem to exhibit weak fluctuations (Fig. S3). The heavier the pollution, the larger fraction of inorganic chemical compositions, which could enhance water-absorbing process to change aqueous concentration $\mathrm{H}^{+}$. 


\section{Relationships between Aerosol Liquid Water, Acidity and CCN Activity}

Fig. 2 shows Aero-pHs as a function of PLWCs, where Aero-pHs mainly range in 1.5-4.0, and PLWCs are in 10$170 \mu \mathrm{g} \mathrm{m}^{-3}$. Aero-pHs increase rapidly with PLWCs until a peak (i.e., 3.5) when RHs are less than $75 \%$ and PLWCs are lower than $20 \mu \mathrm{g} \mathrm{m}^{-3}$, whereas Aero-pHs seem to increase slowly with PLWCs and finally maintain a maximum (i.e., 3.7) when PLWCs dramatically rise up to $165 \mu \mathrm{g} \mathrm{m}^{-3}$ under conditions of RHs beyond $75 \%$. As shown in Fig. 3, at high $\mathrm{PM}_{2.5}$ levels of exceeding $50 \mu \mathrm{g} \mathrm{m}^{-3}$, the percentages of integrated WSIM in $\mathrm{PM}_{2.5}$ ascend with increasing Aero-pHs, with a high correlation coefficient $\left(\mathrm{R}^{2}=0.61\right)$, indicating a strong interaction exists between WSIM and aerosol acidity. However, at $\mathrm{PM}_{2.5}$ less than $50 \mu \mathrm{g} \mathrm{m}^{-3}$, there are not an obvious relationship between WSIM/PM ${ }_{2.5}$ and Aero-pHs except for an obscure increasing trend. As shown in Fig. 4(a), CCN increase sharply with PLWCs when PLWCs are lower than $40 \mu \mathrm{g} \mathrm{m}^{-3}$ at low $\mathrm{PM}_{2.5}$ levels, whereas $\mathrm{CCN}$ remains almost at a high loading (e.g., $5000 \mathrm{~cm}^{-3}$ ) at high $\mathrm{PM}_{2.5}$ levels. In addition, $\mathrm{CCN}$ increase with Aero-pHs at any $\mathrm{PM}_{2.5}$ levels, and the growth velocity (slope) is greater at high $\mathrm{PM}_{2.5}$ levels (Fig. 4(b)). These results reveal that CCN links closely with Aero-pH, in particular under conditions of high PM loading (e.g., WSIM), and they both vary rapidly at low PLWC (i.e., low RH and PM) and almost invariably at high PLWC (i.e., high RH and PM).

During the whole campaign, the polluted periods can be distinguished six distinct rise-and-fall fluctuations like sea waves, i.e., $a-f$ stages labeled in Fig. 1, representative of fast growth, peak and decline in PM. The $a-c$ stages occurred in the first episode coinciding with the New Year holiday, an abrupt pollution characterized by rapid outbreak, persistence and high $\mathrm{PM}_{2.5}$ levels, while the $d-f$ stages were in the second episode after rain (5 Jan.), a gradual pollution with moderate $\mathrm{PM}_{2.5}$ levels. It should be noted that here $\triangle \mathrm{CCN}$ refers to the difference of CCNs under different supersaturation conditions ( $\mathrm{SS}=0.8$ vs. 0.1 , thereafter), which not only

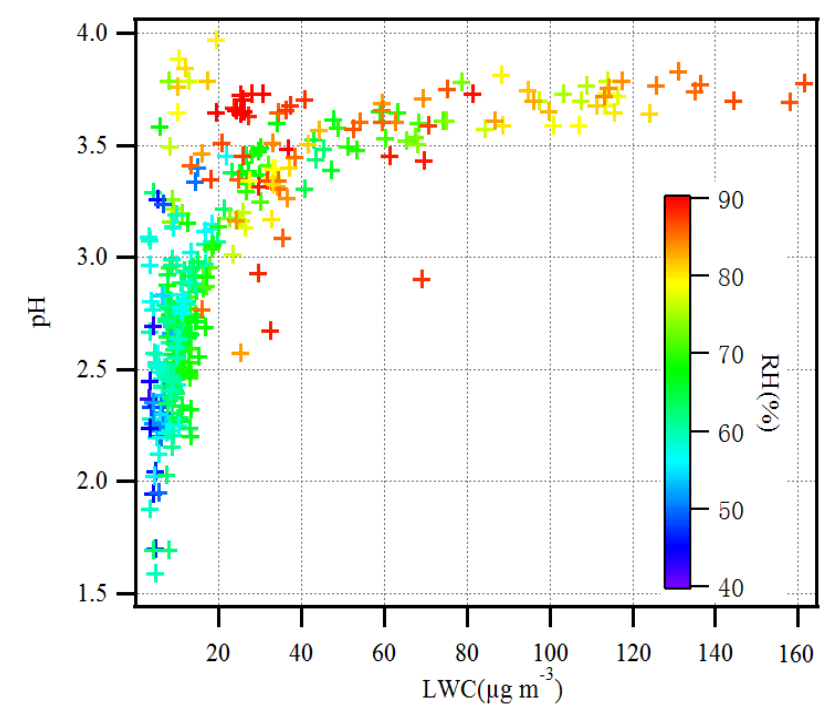

Fig. 2. Aerosol acidity $(\mathrm{pH})$ as a function of aerosol liquid water content (LWC). The crosses are colored according to relative humidity $(\mathrm{RH})$.

could reflect the changes of CCNs at any SS, but also was helpful to understand some potential CCNs that shift from hydrophobic to hygroscopic along with reinforcing SS (e.g., carbonaceous particles), and in the future more measurements are needed to confirm this phenomenon. In the case of the a stage that $\mathrm{PM}_{2.5}$ mass per volume increases by $78.3 \mu \mathrm{g} \mathrm{m}^{-3}$ for 5 hours (Fig. 1), once air pollution bursts, $\mathrm{PM}_{2.5}, \mathrm{CCN}$, $\mathrm{CN}$ and Aero-pH rapidly increase in company with enhanced $\mathrm{RH}, \mathrm{NO}_{x}, \mathrm{SO}_{2}$ and $\mathrm{NH}_{3}$ starting at 18:00 (LT, thereafter) on 2 Jan., and then peak in about 4 hours (23:00, near midnight), and the bottom-to-top increments are $1.32 \%, 65 \%, 107 \%$ and $141 \%$ for Aero-pH, $\mathrm{CCN}, \mathrm{PM}_{2.5}$ and $\triangle \mathrm{CCN}$, respectively. In addition, RH gets peak at 03:00 on 3 Jan., SOR increases continuously since pollution kick-off time and then grows up slowly at a high level after 00:00, and NOR rises up
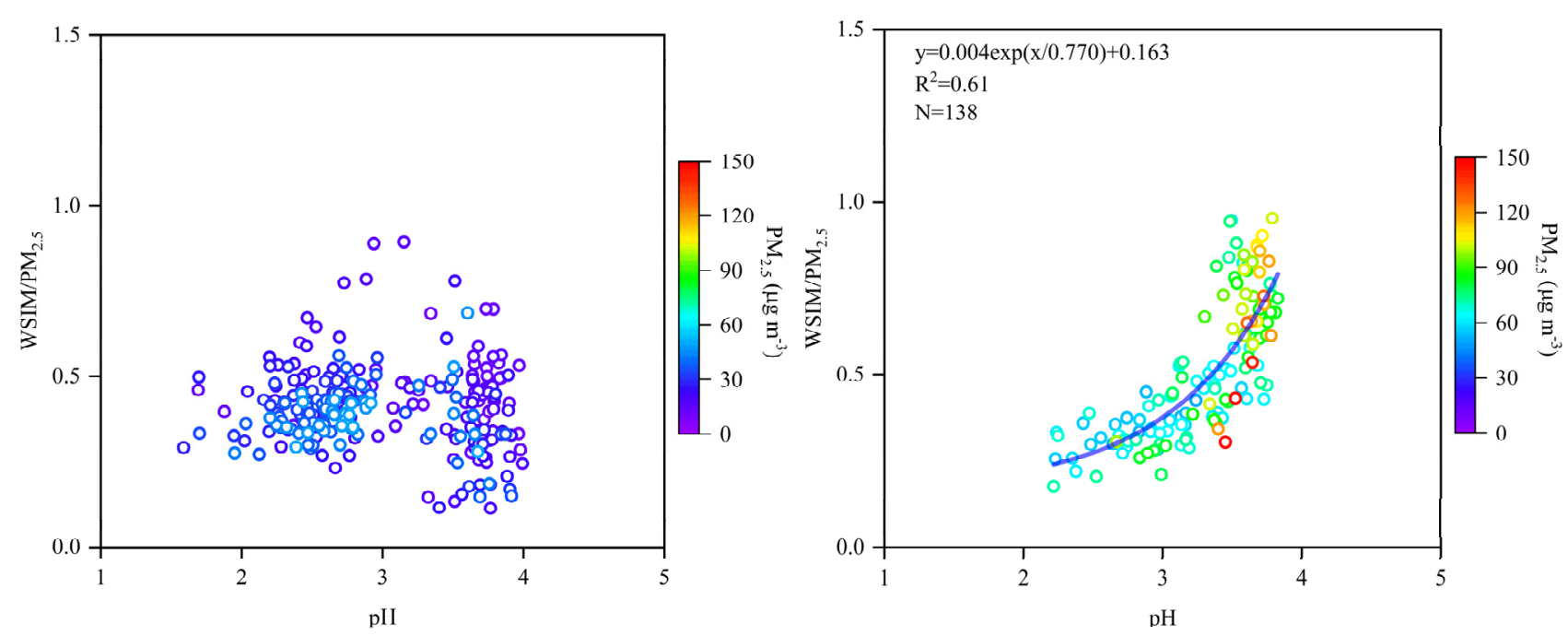

Fig. 3. Fractions of water soluble inorganic matter (WSIM) in $\mathrm{PM}_{2.5}$ as a function of aerosol acidity (pH). The circles are colored according to $\mathrm{PM}_{2.5}$ concentrations. 

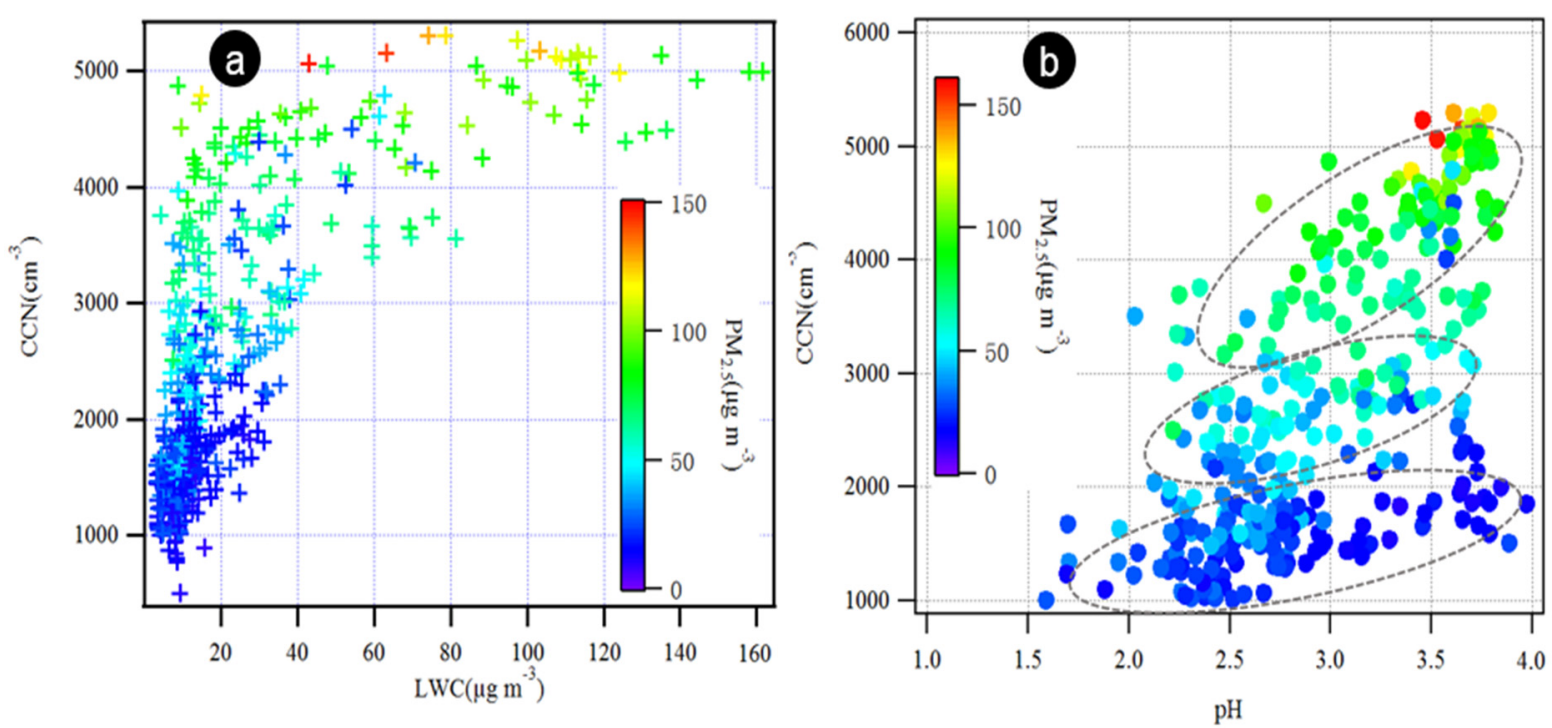

Fig. 4. Cloud condensation nuclei $(\mathrm{CCN})$ at supersaturation 0.4 as a function of (a) aerosol liquid water content (LWC) and (b) aerosol acidity ( $\mathrm{pH}$ ). The crosses (a) and circles (b) are colored according to $\mathrm{PM}_{2.5}$ concentrations.

continuously until reaching maxima at 05:00. Subsequently, WSIM and PLWC increase to high levels around 03:00 04:00, and AR arrives peak at 06:00, implying a distinct time delay (Fig. 1). Noticeably, among all increasing inorganic ions, $\mathrm{Cl}^{-}$is the first to reach peak in 3 hours from kick-off time, $\mathrm{SO}_{4}{ }^{2-}$ is the second in 8 hours, and subsequently $\mathrm{NO}_{3}$ and $\mathrm{NH}_{4}{ }^{+}$reach peaks after next 2 and 4 hours, respectively. Similar to the a stage, during the d stage, $\mathrm{CCN}$ and Aero-pH reach maxima at 22:00 on $7 \mathrm{Jan}$., RH gets peak at 02:00 on 8 Jan., PLWC reaches maximum at 3:00, and subsequently $\mathrm{AR}$ arrives peak at 04:00. However, although $\mathrm{NO}_{x}$ and $\mathrm{SO}_{2}$ increase rapidly, $\mathrm{NH}_{3}$ and $\mathrm{NOR}$ have insignificant changes, and conversely SOR decreases (Fig. 1). During the $\mathrm{b}$ and $\mathrm{e}$ stages, all of CCN, Aero-pH, RH, PLWC and AR also show an increasing trend, and usually involve a time lag. Overall, there are several obvious features of pollution eruption: First, $\mathrm{CCN}$, Aero-pH and $\mathrm{PM}_{2.5}$ vary almost synchronously, as do AR, PLWC and WSIM; second, AR arriving maximum always tends to be 6-7 hours later than $\mathrm{CCN}$; third, $\mathrm{RH}$ rapid growth possibly plays a key role in PLWC accumulation, about 1-2 hours ahead of the latter; fourth, conversion of trace gases seems to far enhance WSIM, especially nitrogen oxides and ammonia; fifth, ammonia may contribute to enlarge Aero- $\mathrm{pH}$.

The Pearl River Delta experienced a transit of two consecutive cold fronts during the whole pollution period, and formed a stable isobaric environment due to weak cold high-pressure, which is conducive to pollutant accumulation. According to air mass backward trajectories (Fig. S4), during the $\mathrm{a}, \mathrm{b}, \mathrm{d}$ and e stages, air flows mainly originate from adjacent continental areas, moving slowly at a very low altitude, and expectedly transport some non-local pollutants to cause pollution formation. However, as for the $\mathrm{c}$ and $\mathrm{f}$ stages, air flows come from oceanic areas, and bring clean air to dilute pollutants and then mitigate pollution. Based on the poor ammonia/rich ammonia method (Tao et al., 2016), linear regression analysis shows that ammonium sulfate is dominated by $\mathrm{NH}_{4} \mathrm{HSO}_{4}$ and $\left(\mathrm{NH}_{4}\right)_{2} \mathrm{SO}_{4}$ in the first episode, but by $\mathrm{NH}_{4} \mathrm{HSO}_{4}$ in the second episode (Fig. S4). Ammonium salts are abundant and partly promote aerosol acidity, indicating that the control of ammonia emission could be critical to further mitigate air pollution.

\section{DISCUSSION}

Stagnant weather conditions cause the rapid formation of air pollution by suppressing diffusion, thereby promoting the gradual accumulation of pollutants in the atmospheric boundary layer, whereas high RH worsens air quality by enhancing particle hygroscopicity and increasing light extinction, thereby degrading atmospheric visibility. This aerosol-radiation-meteorology feedback loop plays an important role in sustaining air pollution, as it changes the thermodynamic structure of the lower atmosphere and prevents vertical convection from developing, thus trapping pollutants within the planetary boundary layer (PBL) (Ding et al., 2016).

Additionally, the PLWC - potentially a critical component in aerosols and a medium for gas precursor chemical reactions - is generally related to $\mathrm{RH}$, particle size, chemical composition and hygroscopicity, with accumulation-mode particles being its largest contributing factor. Sulfur dioxide $\left(\mathrm{SO}_{2}\right)$ that oxidizes into sulfate $\left(\mathrm{SO}_{4}{ }^{2-}\right)$ via heterogeneous reactions, as well as chloride ions $\left(\mathrm{Cl}^{-}\right)$, triggers an increase in WSIM. Consequently, during conditions of abundant nitric oxide $\left(\mathrm{NO}_{x}\right)$ or high $\mathrm{RH}$, the heterogeneous reactions of $\mathrm{N}_{2} \mathrm{O}_{5}$ or $\mathrm{SO}_{2}$ and the aqueous-phase reactions of $\mathrm{SO}_{2}$ oxidation via $\mathrm{NO}_{2}$ or $\mathrm{O}_{3}$ at night (Sun et al., 2016) accelerate the production of sulfate $\left(\mathrm{SO}_{4}{ }^{2-}\right)$, nitrate $\left(\mathrm{NO}_{3}{ }^{-}\right)$and nitrite $\left(\mathrm{NO}_{2}{ }^{-}\right)$and dramatically raise the amount of WSIM. In addition, the elevated levels of ammonia $\left(\mathrm{NH}_{3}\right)$ significantly favor the formation of ammonium $\left(\mathrm{NH}_{4}{ }^{+}\right)$, sulfate $\left(\mathrm{SO}_{4}{ }^{2-}\right)$ and nitrate $\left(\mathrm{NO}_{3}{ }^{-}\right)$via neutralization-although $\mathrm{SO}_{4}{ }^{2-}$ likely competes with $\mathrm{NO}_{3}{ }^{-}$for $\mathrm{NH}_{4}{ }^{+}$in reactions - further increasing 
the WSIM. Notably, low temperatures and high RH facilitate the gas-to-particle partitioning of aerosols (e.g., $\mathrm{HNO}_{3}$ and $\mathrm{NH}_{4} \mathrm{NO}_{3}$ ), generating high nitrate during winter. According to the ionic equilibrium, the increased amount of WSIM in aged aerosols is conducive to modifying the aerosol acidity (i.e., Aero-pH) as well as the aerosol water content (i.e., PLWC). The feedback between aerosol chemical reactions, particle water content and aerosol acidity (chemistry-wateracidity) significantly contributes to the rapid increase in the WSIM, PLWC and Aero-pH, which then enhances aerosol activation (i.e., AR). Since the rapid onset of pollution is driven by the aforementioned chemical mechanisms, the aerosol acidity and the aerosol water content qualify as indictors of the activated aerosols (number) and the aerosols' $\mathrm{CCN}$ activity (efficiency), respectively, during this period.

Although the pollution cases used in this study were limited, our findings nevertheless offer new information on the swift formation of particle pollution characterized by secondary aerosols and suggest a possible approach to tracking or characterizing its effects on the activation of aerosols into $\mathrm{CCN}$ without requiring $\mathrm{CCN}$ or aerosol number measurements. More examples, however, are necessary to evaluate the efficiency and accuracy of this method.

\section{ACKNOWLEDGMENTS}

This research is supported by the National Key R\&D Program of China (2017YFC1501405 and 2016YFC0202003), the National Natural Science Foundation of China (41775129, 91637101, 21577021 and 91843301) and partly by the Science and Technology Commission of Shanghai Municipality (16ZR1431700).

\section{SUPPLEMENTARY MATERIAL}

Supplementary data associated with this article can be found in the online version at http://www.aaqr.org.

\section{REFERENCES}

An, Z., Huang, R.J., Zhang, R., Tie, X., Li, G., Cao, J., Zhou, W., Shi, Z., Han, Y., Gu, Z. and Ji, Y. (2019). Severe haze in northern China: A synergy of anthropogenic emissions and atmospheric processes. Proc. Natl. Acad. Sci. U.S.A. 116: 8657-8666.

Battaglia, M.A. Jr., Weber, R.J., Nenes, A. and Hennigan, C.J. (2019). Effects of water-soluble organic carbon on aerosol pH. Atmos. Chem. Phys. Discuss. doi: 10.5194/acp2019-344, in Review.

Behera, S.N. and Sharma, M. (2012). Transformation of atmospheric ammonia and acid gases into components of $\mathrm{PM}_{2.5}$ : An environmental chamber study. Environ. Sci. Pollut. Res. 19: 1187-1197.

Bollasina, M.A., Ming, Y. and Ramaswamy, V. (2011). Anthropogenic aerosols and the weakening of the south Asian summer monsoon. Science 334: 502-505.

Bougiatioti, A., Nikolaou, P., Stavroulas, I., Kouvarakis, G., Weber, R., Nenes, A., Kanakidou, M. and Mihalopoulos, N. (2016). Particle water and $\mathrm{pH}$ in the eastern
Mediterranean: Source variability and implications for nutrient availability. Atmos. Chem. Phys. 16: 4579-4591. Che, H.C., Zhang, X.Y., Wang, Y.Q., Zhang, L., Shen, X.J., Zhang, Y.M., Ma, Q.L., Sun, J.Y., Zhang, Y.W. and Wang, T.T. (2016). Characterization and parameterization of aerosol cloud condensation nuclei activation under different pollution conditions. Sci. Rep. 6: 24497.

Cheng, Y., Zheng, G., Wei, C., Mu, Q., Zheng, B., Wang, Z., Gao, M., Zhang, Q., He, K., Carmichael, G., Pöschl, U. and $\mathrm{Su}, \mathrm{H}$. (2016). Reactive nitrogen chemistry in aerosol water as a source of sulfate during haze events in China. Sci. Adv. 2: e1601530.

Clegg, S.L., Brimblecombe, P. and Wexler, A.S. (1998). Thermodynamic model of the system $\mathrm{H}^{+}-\mathrm{NH}_{4}^{+}-\mathrm{Na}^{+}-$ $\mathrm{SO}_{4}{ }^{2-}-\mathrm{NO}_{3}{ }^{-}-\mathrm{Cl}^{-}-\mathrm{H}_{2} \mathrm{O}$ at 298.15 K. J. Phys. Chem. A 102: 2155-2171.

Cubison, M.J., Ervens, B., Feingold, G., Docherty, K.S., Ulbrich, I.M., Shields, L., Prather, K., Hering, S. and Jimenez, J.L. (2008). The influence of chemical composition and mixing state of Los Angeles urban aerosol on CCN number and cloud properties. Atmos. Chem. Phys. 8: 5649-5667.

Ding, A.J., Huang, X., Nie, W., Sun, J.N., Kerminen, V.M., Petäjä, T., Su, H., Cheng, Y.F., Yang, X.Q., Wang, M.H., Chi, X.G., Wang, J.P., Virkkula, A., Guo, W.D., Yuan, J., Wang, S.Y., Zhang, R.J., Wu, Y.F., Song, Y., Zhu, T., Zilitinkevich, S., Kulmala, M. and Fu, C.B. (2016). Enhanced haze pollution by black carbon in megacities in China. Geophys. Res. Lett. 43: 2873-2879.

Ding, J., Zhao, P., Su, J., Dong, Q., Du, X. and Zhang, Y. (2019). Aerosol $\mathrm{pH}$ and its driving factors in Beijing. Atmos. Chem. Phys. 19: 7939-7954.

Elser, M., Huang, R.J., Wolf, R., Slowik, J.G., Wang, Q., Canonaco, F., Li, G., Bozzetti, C., Daellenbach, K.R., Huang, Y., Zhang, R., Li, Z., Cao, J., Baltensperger, U., El-Haddad, I. and Prévôt, A.S.H. (2016). New insights into $\mathrm{PM}_{2.5}$ chemical composition and sources in two major cities in China during extreme haze events using aerosol mass spectrometry. Atmos. Chem. Phys. 16: 3207-3225.

Ganbavale, G., Zuend, A., Marcolli, C. and Peter, T. (2015). Improved AIOMFAC model parameterisation of the temperature dependence of activity coefficients for aqueous organic mixtures. Atmos. Chem. Phys. 15: 447-493.

Guo, H., Xu, L., Bougiatioti, A., Cerully, K.M., Capps, S.L., Hite Jr, J.R., Carlton, A.G., Lee, S.H., Bergin, M.H., Ng, N.L., Nenes, A. and Weber, R.J. (2015). Fine-particle water and $\mathrm{pH}$ in the southeastern United States. Atmos. Chem. Phys. 15: 5211-5228.

Guo, H., Weber, R.J. and Nenes, A. (2017). High levels of ammonia do not raise fine particle $\mathrm{pH}$ sufficiently to yield nitrogen oxide-dominated sulfate production. Sci. Rep. 7: 12109

Guo, H., Nenes, A. and Weber, R.J. (2018). The underappreciated role of nonvolatile cations in aerosol ammonium-sulfate molar ratios. Atmos. Chem. Phys. 18: 17307-17323.

He, K., Zhao, Q., Ma, Y., Duan, F., Yang, F., Shi, Z. and Chen, G. (2012). Spatial and seasonal variability of $\mathrm{PM}_{2.5}$ 
acidity at two Chinese megacities: insights into the formation of secondary inorganic aerosols. Atmos. Chem. Phys. 12: 1377-1395.

Hennigan, C.J., Izumi, J., Sullivan, A.P., Weber, R.J. and Nenes, A. (2015). A critical evaluation of proxy methods used to estimate the acidity of atmospheric particles, Atmos. Chem. Phys. 15: 2775-2790.

Hodas, N., Sullivan, A.P., Skog, K., Keutsch, F.N., Collett, J.L., Decesari, S., Facchini, M.C., Carlton, A.G., Laaksonen, A. and Turpin, B.J. (2014). Aerosol liquid water driven by anthropogenic nitrate: Implications for lifetimes of water-soluble organic gases and potential for secondary organic aerosol formation. Environ. Sci. Technol. 48: $11127-11136$

Hu, G., Zhang, Y., Sun, J., Zhang, L., Shen, X., Lin, W. and Yang, Y. (2014). Variability, formation and acidity of water-soluble ions in $\mathrm{PM}_{2.5}$ in Beijing based on the semicontinuous observations. Atmos. Res. 145: 1-11.

Huang, R.J., Zhang, Y., Bozzetti, C., Ho, K.F., Cao, J.J., Han, Y., Daellenbach, K.R., Slowik, J.G., Platt, S.M., Canonaco, F., Zotter, P., Wolf, R., Pieber, S.M., Bruns, E.A., Crippa, M., Ciarelli, G., Piazzalunga, A., Schwikowski, M., Abbaszade, G., Schnelle-Kreis, J., Zimmermann, R., An, Z., Szidat, S., Baltensperger, U., Haddad, I.E. and Prévôt, A.S.H. (2014). High secondary aerosol contribution to particulate pollution during haze events in China. Nature 514: 218-222.

Jimenez, J.L., Canagaratna, M.R., Donahue, N.M., Prevot, A.S.H., Zhang, Q., Kroll, J.H., DeCarlo, P.F., Allan, J.D., et al. (2009). Evolution of organic aerosols in the atmosphere. Science 326: 1525-1529.

Khlystov, A., Stanier, C.O., Takahama, S. and Pandis, S.N. (2005). Water content of ambient aerosol during the Pittsburgh Air Quality Study. J. Geophys. Res. 110: D07S10, doi: 10.1029/2004JD004651.

Leng, C., Zhang, Q., Zhang, D., Xu, C., Cheng, T., Zhang, R., Tao, J., Chen, J., Zha, S., Zhang, Y., Li, X., Kong, L. and Gao, W. (2014). Variation of cloud condensation nuclei (CCN) and aerosol activity during fog-haze episode: A case study from Shanghai. Atmos. Chem. Phys. 14: 12499-12512.

Liu, M., Song, Y., Zhou, T., Xu, Z., Yan, C., Zheng, M., Wu, Z., Hu, M., Wu, Y. and Zhu, T. (2017). Fine particle pH during severe haze episodes in northern China. Geophys. Res. Lett. 44: 5213-5221.

Meng, Z., Seinfeld, J.H., Saxena, P. and Kim, Y.P. (1995). Atmospheric gas-aerosol equilibrium: IV. Thermodynamics of carbonates. Aerosol Sci. Technol. 23: 131-154.

Mochida, M., Kuwata, M., Miyakawa, T., Takegawa, N., Kawamura, K. and Kondo, Y. (2006). Relationship between hygroscopicity and cloud condensation nuclei activity for urban aerosols in Tokyo. J. Geophys. Res. 111: D23204.

Nenes, A., Pandis, S.N. and Pilinis, C. (1998). ISORROPIA: A new thermodynamic equilibrium model for multiphase multicomponent inorganic aerosols. Aquat. Geochem. 4: $123-152$.

Nguyen, T.K.V., Zhang, Q., Jimenez, J.L., Pike, M. and Carlton, A.G. (2016). Liquid water: Ubiquitous contributor to aerosol mass. Environ. Sci. Technol. Lett. 3: 257-263.

Poschl, U., Rose, D. and Andreae, M. (2009). Climatologies of cloud-related aerosols-Part 2: Particle hygroscopicity and cloud condensation nuclei activity. Clouds in the Perturbed Climate System, MIT Press, Cambridge, pp. 57-72.

Sun, J. and Ariya, P.A. (2006). Atmospheric organic and bio-aerosols as cloud condensation nuclei $(\mathrm{CCN})$ : A review. Atmos. Environ. 40: 795-820.

Sun, Y., Chen, C., Zhang, Y., Xu, W., Zhou, L., Cheng, X., Zheng, H., Ji, D., Li, J., Tang, X., Fu, P. and Wang, Z. (2016). Rapid formation and evolution of an extreme haze episode in Northern China during winter 2015. Sci. Rep. 6: 27151.

Tan, H., Cai, M., Fan, Q., Liu, L., Li, F., Chan, P.W., Deng, $\mathrm{X}$. and $\mathrm{Wu}, \mathrm{D}$. (2017). An analysis of aerosol liquid water content and related impact factors in Pearl River Delta. Sci. Total Environ. 579: 1822-1830.

Tao, J., Zhang, L., Ho, K., Zhang, R., Lin, Z., Zhang, Z., Lin, M., Cao, J., Liu, S. and Wang, G. (2014). Impact of $\mathrm{PM}_{2.5}$ chemical compositions on aerosol light scattering in Guangzhou-the largest megacity in South China. Atmos. Res. 135-136: 48-58.

Tao, Y., Ye, X., Ma, Z., Xie, Y., Wang, R., Chen, J., Yang, $X$. and Jiang, S. (2016). Insights into different nitrate formation mechanisms from seasonal variations of secondary inorganic aerosols in Shanghai. Atmos. Environ. 145: 1-9.

Wang, G., Zhang, R., Gomez, M.E., Yang, L., Levy Zamora, M., Hu, M., Lin, Y., Peng, J., Guo, S., Meng, J., Li, J., Cheng, C., Hu, T., Ren, Y., Wang, Y., Gao, J., Cao, J., An, Z., Zhou, W., Li, G., Wang, J., Tian, P., MarreroOrtiz, W., Secrest, J., Du, Z., Zheng, J., Shang, D., Zeng, L., Shao, M., Wang, W., Huang, Y., Wang, Y., Zhu, Y., Li, Y., Hu, J., Pan, B., Cai, L., Cheng, Y., Ji, Y., Zhang, F., Rosenfeld, D., Liss, P.S., Duce, R.A., Kolb, C.E. and Molina, M.J. (2016). Persistent sulfate formation from London Fog to Chinese haze. Proc. Natl. Acad. Sci. U.S.A. 113: 13630-13635.

Weber, R.J., Guo, H., Russell, A.G. and Nenes, A. (2016). High aerosol acidity despite declining atmospheric sulfate concentrations over the past 15 years. Nat. Geosci. 9: 282.

Wong, J.P.S., Lee, A.K.Y. and Abbatt, J.P.D. (2015). Impacts of sulfate seed acidity and water content on isoprene secondary organic aerosol formation. Environ. Sci. Technol. 49: 13215-13221.

Wu, Z., Wang, Y., Tan, T., Zhu, Y., Li, M., Shang, D., Wang, H., Lu, K., Guo, S., Zeng, L. and Zhang, Y. (2018). Aerosol liquid water driven by anthropogenic inorganic salts: Implying its key role in haze formation over the North China Plain. Environ. Sci. Technol. Lett. 5: 160166.

Xie, X., Zhang, X., Wang, Y., Lyu, R., Zhou, G., Cheng, T., Liu, Y., Peng, Y., He, Q., Gao, W., Li, X. and Zhang, Q. (2019). Effects of shipping-originated aerosols on physical cloud properties over marine areas near East China. Aerosol Air Qual. Res. 19: 1471-1482.

Xu, L., Guo, H., Boyd, C.M., Klein, M., Bougiatioti, A., Cerully, K.M., Hite, J.R., Isaacman-VanWertz, G., 
Kreisberg, N.M., Knote, C., Olson, K., Koss, A., Goldstein, A.H., Hering, S.V., de Gouw, J., Baumann, K., Lee, S.H., Nenes, A., Weber, R.J. and Ng, N.L. (2015). Effects of anthropogenic emissions on aerosol formation from isoprene and monoterpenes in the southeastern United States. Proc. Natl. Acad. Sci. U.S.A. 112: 37-42.

Yang, F., Tan, J., Zhao, Q., Du, Z., He, K., Ma, Y., Duan, F., Chen, G. and Zhao, Q. (2011). Characteristics of $\mathrm{PM}_{2.5}$ speciation in representative megacities and across China. Atmos. Chem. Phys. 11: 5207-5219.

Zhang, R., Wang, G., Guo, S., Zamora, M.L., Ying, Q., Lin, Y., Wang, W., Hu, M. and Wang, Y. (2015). Formation of urban fine particulate matter. Chem. Rev. 115: 38033855.

Zheng, M., Salmon, L.G., Schauer, J.J., Zeng, L., Kiang, C.S., Zhang, Y. and Cass, G.R. (2005). Seasonal trends in $\mathrm{PM}_{2.5}$ source contributions in Beijing, China. Atmos. Environ. 39: 3967-3976.

Received for review, September 26, 2019

Revised, October 28, 2019

Accepted, November 1, 2019 